\title{
Risk and the distribution of human capital
}

\author{
Daniele Checchi a \\ University of Milan
}

\author{
and \\ Cecilia García-Peñalosa \\ GREQAM and CNRS $^{\text {b }}$, Marseille
}

file name: checchi-penalosa(v2).doc

version: July 2002

\begin{abstract}
We develop a model in which aggregate production risk affects individuals' education decisions, and hence determines both the average level of education and the distribution of human capital. The model predicts that greater risk should be associated with greater educational inequality and a lower average attainment. An empirical test using panel data supports this conclusion.
\end{abstract}

JEL classification numbers: I20; J24; O15; N30

Key words: human capital, inequality, macroeconomic volatility.

a University of Milan, Department of Economics, via Conservatorio 7, 20124 Milan-Italy. Email:daniele.checchi@unimi.it

b GREQAM, Centre de la Vieille Charité, 2 rue de la Charité, 13002 Marseille, France. Email: penalosa@ehess.cnrs-mrs.fr 


\section{Introduction}

Recent empirical studies have shown that economic volatility is an important factor affecting a number of macroeconomic variables. Greater volatility has been found to reduce the average growth rate and secondary schooling enrolment rates, while it tends to increase income inequality (see, respectively, Ramey and Ramey, 1995; Flug, Spilimbergo, and Wachtenheim, 1998; Breen and GarcíaPeñalosa, 2002). In this paper we examine a further possible effect of volatility, namely its effect on the distribution of human capital.

We start by presenting a model, which extends the seminal work of Galor and Zeira (1993) by introducing uncertainty. In our setup, the absence of long-run equality is driven not by credit market imperfections, but rather by agents' aversion to risk. For Galor and Zeira long-run macroeconomic performance depends on initial inequality because parental wealth creates the possibility of investing in education; in our case inherited wealth plays the role of insurance against the risk of studying and hence determines the willingness to become educated. Our model implies that the long-run distribution of human capital depends not only on the initial distribution of wealth, but also on aggregate production risk. Economies that are more volatile exhibit fewer average years of education and a greater degree of educational inequality.

Previous work on the effect of risk on education has shown that in principle uncertainty has an ambiguous effect on individual incentives to study. Levhari and Weiss (1974) prove that there are two sufficient conditions under which greater risk will reduce investment in education: that the variance of earnings is increasing with the level of schooling, and that agents have decreasing absolute riskaversion. Our model makes both assumptions, implying that agents reduce their education investment when uncertainty increases. Furthermore, Levhari and Weiss also show that under these assumptions, greater non-labour wealth will raise educational investment; a result we will use to link the initial distribution of wealth to the long-run degree of educational inequality.

The second part of our paper provides empirical evidence on a positive relationship between macroeconomic volatility and educational inequality. Our empirical test consists of analysing the variables correlated with educational achievement and its distribution in a sample of developed and developing countries. Closest to our paper is the work of Flug, Spilimbergo and Wachtenheim (1998), who find a correlation between secondary school enrolment rates and growth volatility. Their focus is on the financial constraints caused by downturns that force individuals to leave schooling, and hence on flows into education. Our model is concerned with the long-run behaviour of the economy and hence seeks to explain the determinants of the stock of education. Furthermore, we are not only interested in explaining average educational attainment but also its distribution. Our results can in fact help understand the strong effect of volatility on the distribution of income reported by Breen and García-Peñalosa (2002): risk increases the dispersion of human capital and hence that of income. 


\section{The model}

\subsection{Elements of the economy}

Firms: Firms produce according to

$$
Y_{t}=A_{t} K_{t}^{\beta} L_{t}^{1-\beta}, \quad 0<\beta<1,
$$

where $K_{t}$ is the capital stock, and $L_{t}$ the number of efficiency units of labour. There are two types of labour, unskilled, denoted $u_{t}$, and skilled, $s_{t}$, which supply 1 and $h$ efficiency units of labour, respectively. They are assumed to be perfect substitutes so that $L_{t}=u_{t}+s_{t} h . A_{t}$ represents the level of productivity at time $t$, which can take two values, $\bar{A}$ and $\underline{A}$, each with probability $1 / 2$. It hence has mean $\mu=(\bar{A}+\underline{A}) / 2$ and variance $\sigma^{2}=(\bar{A}-\underline{A})^{2} / 4$.

Firms decide on their stock of capital before the shock is realised, but pay wages after production takes place. They are risk neutral, hence they equate the (given) world interest rate, $r$, to the expected marginal product of capital. This implies a capital labour ratio of $K_{t} / L_{t}=(\mu \beta / r)^{1 /(1-\beta)}$. Differentiating the production function and substituting for the capital/labour ratio, we obtain that the wage per efficiency unit in period $t$ is $\omega_{t}=A_{t} w$, where $w$ is a constant. ${ }^{1}$

Consumers: The population is normalised to one. Each consumer lives for two periods; chooses whether or not to study in the first one, and works in the second. Her entire consumption, $c$, takes place in the second period, and she also leaves a bequest $b$ to her offspring. The utility of agent $i$ is assumed to be

$$
U_{i t}=(1-\alpha) \ln c_{i t}+\alpha \ln b_{i t} .
$$

Denote her income in the good state of the world by $\bar{Y}_{i t}$, and her income in the bad state by $\underline{Y}_{i t}$. She then maximises her expected utility,

$$
\begin{aligned}
& \max E U_{i t}=\frac{1}{2}\left[(1-\alpha) \ln \bar{c}_{i t}+\alpha \ln \bar{b}_{i t}\right]+\frac{1}{2}\left[(1-\alpha) \ln \underline{c}_{i t}+\alpha \ln \underline{b}_{i t}\right] \\
& \text { subject to } \bar{Y}_{i t}=\bar{c}_{i t}+\bar{b}_{i t} \\
& \underline{Y}_{i t}=\underline{c}_{i t}+\underline{b}_{i t}
\end{aligned}
$$

where a bar above (below) a variable indicates its value in the good (bad) state of the world. The solution to this problem implies that, at any time, a fraction $\alpha$ of income is bequeathed and a fraction $(1-\alpha)$ is consumed. We can then express expected utility as

$$
E U_{i t}=\ln (1-\alpha)^{1-\alpha} \alpha^{\alpha}+1 / 2 l\left[n \bar{Y}_{i t}+\ln \underline{Y}_{i t}\right] .
$$

\footnotetext{
${ }^{1}$ Specifically, $w=(1-\beta)(\mu \beta / r)^{\beta /(1-\beta)}$.
} 
Education: In the first period of life, an agent may choose not to study. She then works as unskilled labour in the second period. Alternatively, she pays a cost $f$, acquires $n$ years of education, and works as a skilled worker. At time $t$ the agent also receives from her parent an inheritance $x_{i t}=b_{i t-1}$. The expected utilities of being unskilled or skilled are, respectively,

$$
\begin{aligned}
& E U_{i t}^{u}=\ln (1-\alpha)^{1-\alpha} \alpha^{\alpha}+\frac{1}{2} \ln \left[\bar{A} w+R x_{i t}\right]+\frac{1}{2} \ln \left[\underline{A} w+R x_{i t}\right] \\
& E U_{i t}^{s}=\ln (1-\alpha)^{1-\alpha} \alpha^{\alpha}+\frac{1}{2} \ln \left[\bar{A} h w+R\left(x_{i t}-f\right)\right]+\frac{1}{2} \ln \left[\underline{A} h w+R\left(x_{i t}-f\right)\right]
\end{aligned}
$$

An agent will choose to study if her expected utility from doing so exceeds that of remaining unskilled. That is, if her inheritance is greater than $x^{*}$, where

$$
x^{*}=\frac{1}{R} \frac{R f[2 \mu h w-R f]-\left(2 \mu \bar{A}-\bar{A}^{2}\right) w^{2}\left(h^{2}-1\right)}{2 \mu(h-1) w-R f}
$$

Inheritance plays the role of insurance. Since agents have decreasing absolute risk-aversion, and since the absolute level of risk associated with becoming skilled is greater than that associated with remaining unskilled, they chose to study only if they have a sufficiently large non-risky income.

\subsection{The long-run wealth levels}

We examine the dynamics of bequests, and consequently of education decisions, graphically in figure 1. The dynamics of bequests for the skilled and unskilled are given by

$$
\begin{aligned}
& x_{i t+1}^{u}=\alpha\left[A_{t} w+R x_{i t}\right] \\
& x_{i t}^{s}=\alpha\left[A_{t} h w+R\left(x_{i t}-f\right)\right]
\end{aligned}
$$

implying an upward-sloping relationship between the bequest received and that bequeathed. Since the technology parameter can take two values, there are two lines along which each type of worker can move in the space $\left[x_{t}, x_{t+1}\right]$ of figure 1 , represented by the four continuous lines. With probability $1 / 2$ we are in the good state, and an individual moves along the upper line; with probability $1 / 2$ she moves along the lower one, corresponding to a bad state. Assuming $\alpha R<1$, these lines will intersect the $45^{0}$ line. All dynasties that start with wealth $x_{i 0}<x^{*}$ will always be unskilled and converge to the same bequest. The long-run bequest is, however, stochastic: it fluctuates between the two fixed points defined by equation (2.7), $\quad \underline{x}^{u}=\alpha \underline{A} w /(1-\alpha R) \quad$ and $\quad \bar{x}^{u}=\alpha \bar{A} w /(1-\alpha R)$, has mean $E\left(x^{u}\right)=\alpha \mu w /(1-\alpha R)$ and variance $\sigma_{u}^{2}=(\alpha w)^{2} \sigma^{2} /\left(1-R^{2}\right)$. Similarly, all members of dynasties with initial wealth above $x^{*}$ will be educated and have long-run bequests that fluctuate between $\underline{x}^{s}$ and 
$\bar{x}^{s}$. The expected bequest and the long-run variance for this group are $E\left(x^{s}\right)=(\alpha \mu h w-\alpha R f) /(1-\alpha R)$ and $\sigma_{s}^{2}=(\alpha h w)^{2} \sigma^{2} /\left(1-R^{2}\right) .^{2}$

Given an initial distribution of bequests, $F(x)$, the long-run number of skilled workers will be given by $1-F\left(x^{*}\right)$. Then, the stock of efficiency labour is $L=F\left(x^{*}\right)+\left(1-F\left(x^{*}\right)\right) h$, and average years of education are $\overline{H C}=n\left(1-F\left(x^{*}\right)\right)$. As we will show in the next section, with only two education groups the Gini coefficient of the distribution of years of education is simply the fraction of the population with no education, $\operatorname{Gini}_{e d}=F\left(x^{*}\right)$. The initial distribution of income thus determines both average educational attainment and the degree of educational inequality.

\subsection{The effect of risk}

Consider now the impact of an increase in risk. We suppose that there is a mean-preserving spread (MPS), taking the form of an increase in $\bar{A}$ and a reduction in $\underline{A}$. This will increase the variance of the technology, which can be expressed as $\sigma^{2}=(\bar{A}-\mu)^{2}$. Greater risk then has two effects. First, the change in $\bar{A}$ and $\underline{A}$ will shift the bequest schedules of each group further apart. The new schedules are depicted by the dotted lines in figure 1. Although the mean bequests of the skilled and the unskilled remain constant, their variance over time rises. Because the level or earnings of educated workers is higher, the increase in the variance of both earnings and bequests is greater for educated than for noneducated individuals. Second, risk will affect the number of individuals that study. Differentiating equation (2.6), we see that a MPS increases the threshold value of inheritance required to study, shifting it from $x *$ to $x * *$. The reason is precisely that although uncertainty has increased for both types of workers, it has increased by more for educated than for uneducated workers. The investment in education has become more risky, and hence greater wealth is needed in order to induce studying. The increase in the threshold value will, for a given initial distribution of wealth, reduce the long-run number of educated workers to $1-F(x * *)$. An economy with a more risky productivity parameter will then exhibit a lower stock of efficiency labour (and hence lower output), fewer average years of education, and a more unequal distribution of human capital.

Two things are worth noting at this point. First, it would be possible to introduce another level of education. It is then straightforward to show that risk reduces the various threshold levels of inheritance required to study. The number of uneducated increases and that of individuals with high-

\footnotetext{
2 There are other possible configurations for the position of the four bequest lines. In those cases, at least one of the schedules would not intersect the $45^{\circ}$ line. This would mean mobility, in the sense that a dynasty that was initially not educated can, in the presence of a good shock become educated, or vice versa. Since there is no other source of heterogeneity in the model, this would imply that in the long-run all individuals would have the same level of wealth and education, and inequalities would disappear.
} 
education falls, ${ }^{3}$ reducing average educational attainment and increasing educational inequality. Second, the introduction of imperfect capital markets would, by increasing the interest rate, further reduce the threshold value of wealth required to study and hence further reduce $\overline{H C}$ and increase Gini $_{e d}$.

\section{Empirical results}

\subsection{Measures of educational inequality and attainment}

The model predicts that, for a given initial distribution of income, countries with higher levels of risk will exhibit fewer average years of education, $\overline{H C}$, and a greater degree of educational inequality, which we measure by the Gini concentration index computed across subgroups of population, Gini $i_{e d}$. When only subgroup averages are known (as it is the case with educational variables, where population is grouped according to the education certificate they hold), the general definition of the Gini concentration index is modified accordingly :

$$
\operatorname{Gini}_{e d}=\frac{1}{2 n^{2} \cdot \overline{H C}} \sum_{i=1}^{N} \sum_{j=1}^{N}\left|n_{i}-n_{j}\right|=\frac{1}{2 \overline{H C}} \sum_{k=1}^{M} \sum_{h=1}^{M}\left|\bar{n}_{k}-\bar{n}_{h}\right| \cdot H C_{k} \cdot H C_{h}
$$

where $N$ is population size, $n_{i}$ the number of years of schooling of individual $i, M$ the number of subgroups, and $\bar{n}_{h}$ the (average) educational attainment in subgroup $h$, which has relative weight $H C_{h}$. The average number of years of schooling in the population is defined as

$$
\overline{H C}=\sum_{k=1}^{M} \bar{n}_{k} H C_{k}
$$

These two measures are negatively correlated. To illustrate this, consider a population with two groups: one has 0 years of education and dimension $(1-H C)$, while the other has $n$ years of education. Average educational attainment is simply $\overline{H C}=n \cdot H C$, and educational inequality is given by

$$
\operatorname{Gini}_{e d}=\frac{2 \cdot[|n-0| \cdot H C \cdot(1-H C)]}{2 \cdot n \cdot H C}=(1-H C), \quad 0<H C \leq 1
$$

The negative correlation holds when we move to three groups in the population, but additional assumptions are required. ${ }^{4}$

\subsection{Data sources and empirical strategy}

\footnotetext{
3 The fraction of individuals with the intermediate level of education may increase or decrease.

${ }^{4}$ Basically, we need to assume that we cannot observe an expansion of population share with secondary education without observing a contemporaneous expansion of the population share with primary education. See Checchi 2001, Appendix 3, for a formal proof of this claim.
} 
Our education measures (including public expenditure on education) are derived from Barro and Lee (1996), which we have extended up to 1995. Data on GDP and its volatility are obtained from Mark.5.6 of Penn's Tables (Summer and Heston 1991) extended to 1995 using UNDP (2001). Data on income inequality are from Deininger and Squire (1996), data on physical capital stocks are from Nehru and Dhareshwar (1993) and data on liquidity measures are from King and Levine (1993). Descriptive statistics are reported in table 1 . In our largest sample we cover 111 countries in 5-year interval over the period 1960-95.

Unfortunately, not all our variables have a temporal dimension. First, our proxy for aggregate risk is the volatility of growth over the period 1960-90. We measure volatility over such a long period because our model is concerned about predicted or long-term risk. Short-term measures would not capture this concept, but rather be a measure of shocks (which could, in principle, also affect human capital accumulation through other channels). Second, we proxy the initial distribution of wealth by the distribution of income in a country averaged over the entire period. Using contemporaneous values is not possible, as the distribution of income depends on that of education and we would have an endogeneity problem (see Checchi, 2001, and Castello and Domenech, 2001). Using lagged values would have discarded a very large number of observations, since the panel on income distribution presents many gaps. The use of income inequality as an explanatory variable serves a second purpose. Educational investment is riskier when earnings differentials are wider and/or when aggregate production is more subject to external shocks (Ljungqvist, 1995). Aggregate shocks are measured by greater growth volatility ; AVGINI can be seen as a proxy for earning differentials, and hence for idiosyncratic risk.

Table 1 - Descriptive statistics - weighed average (weights=population) $-1960-95$

\begin{tabular}{c|cccc|cc} 
Variable & Mean & Std.Dev. & Min & Max & $\begin{array}{c}\text { countries } \\
\text { max sample }\end{array}$ & $\begin{array}{c}\text { observations } \\
\text { max sample }\end{array}$ \\
\hline GINIED & 49.62 & 23.85 & 5.10 & 99.52 & 117 & 848 \\
HC & 4.56 & 2.80 & 0.04 & 12 & 111 & 775 \\
GDP & 4025.04 & 4532.0 & 288 & 24979.3 & 111 & 775 \\
SDGDP & 4.89 & 2.07 & 1.74 & 15.57 & 111 & 775 \\
AVGINI & 38.70 & 7.74 & 23.93 & 62.23 & 96 & 685 \\
KY & 2.36 & 0.63 & 0.36 & 7.43 & 85 & 625 \\
LLY & 0.392 & 0.24 & 0.10 & 1.50 & 90 & 662
\end{tabular}

\footnotetext{
Variable legend:

GINIED $=$ Gini index of educational attainment (see equation 3.1)

$\mathrm{HC} \quad=$ Average educational attainment in the population - years of schooling ( see equation 3.2)

GDP $\quad=$ Gross domestic product per capita (1985 US dollar)

SDGDP = Average of 3-year moving standard deviation of growth rate of GDP over 1960-90

AVGINI = Gini index of income inequality - country means (corrected for recipient unit and income/consumption)

KY $\quad=$ Physical capital/output ratio

LLY $\quad=$ liquid liability over GDP (average over the period 1960-89)
} 
Given the impossibility of using a country fixed-effect estimator because of the presence of country averages, we resort to using a population-weighed least-square estimator, with robust and country-clustered standard errors. ${ }^{5}$ We control for years and broad regions in all regression equations.

\subsection{Results}

Our estimates are reported in tables 2 (average educational attainment) and 3 (educational inequality). We start in first column with the largest available sample, showing the negative correlation between aggregate risk and HC, and the positive one between volatility and GINIED. We then introduce our measure of financial depth and the Gini of income. Income inequality is negatively correlated with educational investment and positively correlated with educational inequality, as expected, while financial depth has the opposite and significant signs.

There are other factors that obviously affect both the demand and the supply of education. The demand of education is higher the higher the expected return on it. Direct estimates of returns to education (from Bils and Klenow, 2000) were not significant and are not reported here. An alternative proxy for the demand of skilled workers, that typically raises the return to education, is provided by the capital/output ratio. This variable is positively associated with average educational attainment and negatively with educational inequality. On the supply side, we tried using of two explanatory variables: the degree of urbanisation, capturing the proximity to school, and (current) public expenditure on education. Unfortunately the latter is only available from 1970, and is more frequently available for richer countries, thus introducing strong distortions in our sample. None of these two variables proved to have a significant impact (results not reported). ${ }^{6}$

It is well known that a good predictor of a country's educational achievement is its level of development. We therefore control for the stage of development of each country using the (log of) current GDP per capita. Columns 4, 5, and 6 of tables 2 and 3 include this variable. The effect of volatility is robust to the inclusion of current output, with the coefficient changing only slightly. However, the coefficient on financial depth loses its significance; this is not surprising given the high correlation between per capita output and financial development both across countries and over time. ${ }^{7}$

\footnotetext{
5 The alternative we have considered is using a population average GEE estimator with robust standard errors. Results are similar, with more statistical significance in $\mathrm{HC}$ regressions and less significance in GINIED regressions. Estimates are available from the authors.

6 This is in line with previous results (eg. Flug et al., 1998) that find no impact of public expenditure on secondary education on secondary enrolment rates.

7 The use of current output yields somewhat different results from the use of initial (i.e. 1960) GDP advocated by other studies. See Flug et al. (1998).
} 


\section{Concluding remarks}

Recent empirical work has shown that risk matters for the behaviour of economic aggregates, such as the average growth rate. The results in this paper suggest another reason why risk has undesirable effects: the presence of uncertainty harms both average educational attainment and its distribution. The estimated coefficients suggest a strong impact: if Chile were to reduce its level of volatility to that of the U.S. (i.e. by 3.8 percentage points) average years of education would increase by almost one year and the Gini coefficient of the distribution of education would fall by 7.9 points. This suggests, not only that reducing volatility is desirable, but also that it is a policy in which the conflict between efficiency and equity, often advocated when macroeconomic reforms are being considered, is absent.

\section{References}

Barro, R., and J.W.Lee. 1996. International measures of schooling years and schooling quality. American Economic Review, Papers and Proceedings 86 (2): 218-23.

Bils, M. and P.Klenow. 2000. Does schooling cause growth? American Economic Review 90(5):1160-83.

Breen, R. and C.García-Peñalosa. 2002. Income inequality and macroeconomic volatility: an empirical investigation. GREQAM working paper.

Checchi, D. 2001. Education inequality and income inequality. LSE-STICERD wp n.52 (downloadable at http://sticerd.lse.ac.uk/dps/darp/DARP52.pdf)

deGregorio, J. and J.W.Lee 1999.Education and income distribution: new evidence from cross-country data. Harvard Institute for International Development, Development discussion paper n.714.

Deininger, K., and L.Squire. 1996. A New Data Set Measuring Income Inequality. World Bank Economic Review 10 (3): 565-591.

Flug, K., A.Spilimbergo and E.Wachtenheim. 1998. Investment in education: do economic volatility and credit constraints matter? Journal of Development Economics 55: 465-481.

King, R. and R.Levine. 1993. Finance and growth: Schumpeter may be right. Quarterly Journal of Economics

Levhari, D., and Y. Weiss. 1974. The Effect of Risk on the Investment of Human Capital. American Economic Review 64 (6): 950-63.

Ljungqvist, L. 1995. Wage structure as implicit insurance on human capital in developed versus underdeveloped countries. Journal of Development Economics 46: 35-50.

Nehru, V., and A. Dhareshwar. 1993. A New Database on Physical Capital Stock: Sources, Methodology and Results. Rivista de Analisis Economico 8 (1): 37-59.

Ram, R. 1990. Educational expansion and schooling inequality: international evidence and some implication. Review of Economics and Statistics :266-273.

Ramey, G. and V.Ramey. 1995. Cross country evidence on the link between volatility and growth. American Economic Review 85(5): 1138-1151.

Summers, R. and A. Heston. 1991. The Penn World table (Mark 5): an expanded set of international comparisons, 1950-1988. Quarterly Journal of Economics 56(2): 327-368.

UNDP 2001. Human development report. Blackwell 
Table 2 - Determinants of average educational attainment - 1960-95

weighed OLS (weights=population) - White-Huber robust standard errors clustered errors (cluster=country) $\mathrm{t}$ statistics in parentheses with $\mathrm{p}<0.05=*, \mathrm{p}<0.01=* *$

\begin{tabular}{|c|c|c|c|c|c|c|}
\hline \# count: & 11 & 80 & 73 & 111 & 80 & 73 \\
\hline \# obs : & 775 & 597 & 547 & 775 & 597 & 547 \\
\hline Depvar: & he & hc & hc & he & hc & hc \\
\hline \multicolumn{7}{|c|}{ - - - - - - - - - - - - - - - - - - - - - - - - - - - - - - - - - - - - - - - - - - - - - - - - - - - - - - - - - - - - - - - - - - - - - - - } \\
\hline sdgdp & $\begin{array}{l}-0.362 * \star \\
(-2.95)\end{array}$ & $\begin{array}{l}-0.203 * \\
(-2.31)\end{array}$ & $\begin{array}{c}-0.204 * \\
(-2.35)\end{array}$ & $\begin{array}{c}-0.211 * \\
(-2.49)\end{array}$ & $\begin{array}{l}-0.228 * * \\
(-2.66)\end{array}$ & $\begin{array}{l}-0.256 * \star \\
(-2.74)\end{array}$ \\
\hline avgini & & $\begin{array}{c}-0.121 * \\
(-2.52)\end{array}$ & $\begin{array}{l}-0.134 * * \\
(-2.73)\end{array}$ & & $\begin{array}{l}-0.083 * * \\
(-2.73)\end{array}$ & $\begin{array}{l}-0.091 * * \\
(-3.13)\end{array}$ \\
\hline $\log (g d p)$ & & & & $\begin{array}{l}2.383 * * \\
(7.13)\end{array}$ & $\begin{array}{l}2.231 * * \\
(6.95)\end{array}$ & $\begin{array}{l}2.595 * * \\
(5.52)\end{array}$ \\
\hline $11 \mathrm{Y}$ & & $\begin{array}{l}3.286 * * \\
(3.02)\end{array}$ & $\begin{array}{l}2.701 * \\
(2.36)\end{array}$ & & & $\begin{array}{r}-1.823 \\
(-1.65)\end{array}$ \\
\hline ky & & & $\begin{array}{l}0.553 * * \\
(2.60)\end{array}$ & & & $\begin{array}{l}0.458 * \\
(2.13)\end{array}$ \\
\hline Constant & Yes & Yes & Yes & Yes & Yes & Yes \\
\hline Years & Yes & Yes & Yes & Yes & Yes & Yes \\
\hline Region & Yes & Yes & Yes & Yes & Yes & Yes \\
\hline 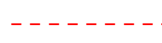 & $\ldots$ & ----- & ------ & ---- & ------ & ------ \\
\hline $\mathrm{R}^{2}$ & 0.668 & 0.771 & 0.778 & 0.84 & 0.854 & 0.864 \\
\hline
\end{tabular}

Table 3 - Determinants of educational inequality - 1960-95

weighed OLS (weights=population) - White-Huber robust standard errors clustered errors (cluster=country) $\mathrm{t}$ statistics in parentheses with $\mathrm{p}<0.05=*, \mathrm{p}<0.01=* *$

\begin{tabular}{|c|c|c|c|c|c|c|}
\hline \# count: & 11 & 80 & 73 & 111 & 80 & 73 \\
\hline \# obs : & 775 & 597 & 547 & 775 & 597 & 547 \\
\hline Depvar: & ginied & ginied & ginied & ginied & ginied & ginied \\
\hline-------- & --------- & --------- & --------- & ---------- & ---------- & ---------- \\
\hline sdgdp & $\begin{array}{l}2.617 * \star \\
(2.87)\end{array}$ & $\begin{array}{l}1.485 * \\
(2.12)\end{array}$ & $\begin{array}{l}1.463 * \\
(2.14)\end{array}$ & $\begin{array}{l}1.682 * \\
(2.54)\end{array}$ & $\begin{array}{l}1.830 * * \\
(2.78)\end{array}$ & $\begin{array}{l}1.771 * * \\
(2.75)\end{array}$ \\
\hline avgini & & $\begin{array}{l}0.727 \star \\
(2.00)\end{array}$ & $\begin{array}{l}0.806 * \\
(2.16)\end{array}$ & & $\begin{array}{c}0.50 \\
(1.85)\end{array}$ & $\begin{array}{l}0.546 * \\
(2.01)\end{array}$ \\
\hline $\log (g d p)$ & & & & $\begin{array}{c}-16.784 * \star \\
(-7.93)\end{array}$ & $\begin{array}{c}-15.875 * \star \\
(-7.68)\end{array}$ & $\begin{array}{c}-15.485 * * \\
(-6.45)\end{array}$ \\
\hline $11 \mathrm{y}$ & & $\begin{array}{c}-28.642 * \star \\
(-3.92)\end{array}$ & $\begin{array}{c}-23.983 * * \\
(-3.12)\end{array}$ & & & $\begin{array}{l}3.015 \\
(0.49)\end{array}$ \\
\hline ky & & & $\begin{array}{l}-4.328 * \\
(-2.30)\end{array}$ & & & $\begin{array}{l}-3.759 * \\
(-2.00)\end{array}$ \\
\hline Constant & Yes & Yes & Yes & Yes & Yes & Yes \\
\hline Years & Yes & Yes & Yes & Yes & Yes & Yes \\
\hline Region & Yes & Yes & Yes & Yes & Yes & Yes \\
\hline $\mathrm{R}^{2}$ & 0.735 & 0.833 & 0.84 & 0.865 & 0.876 & 0.882 \\
\hline
\end{tabular}


Figure 1:

The dynamics of bequests

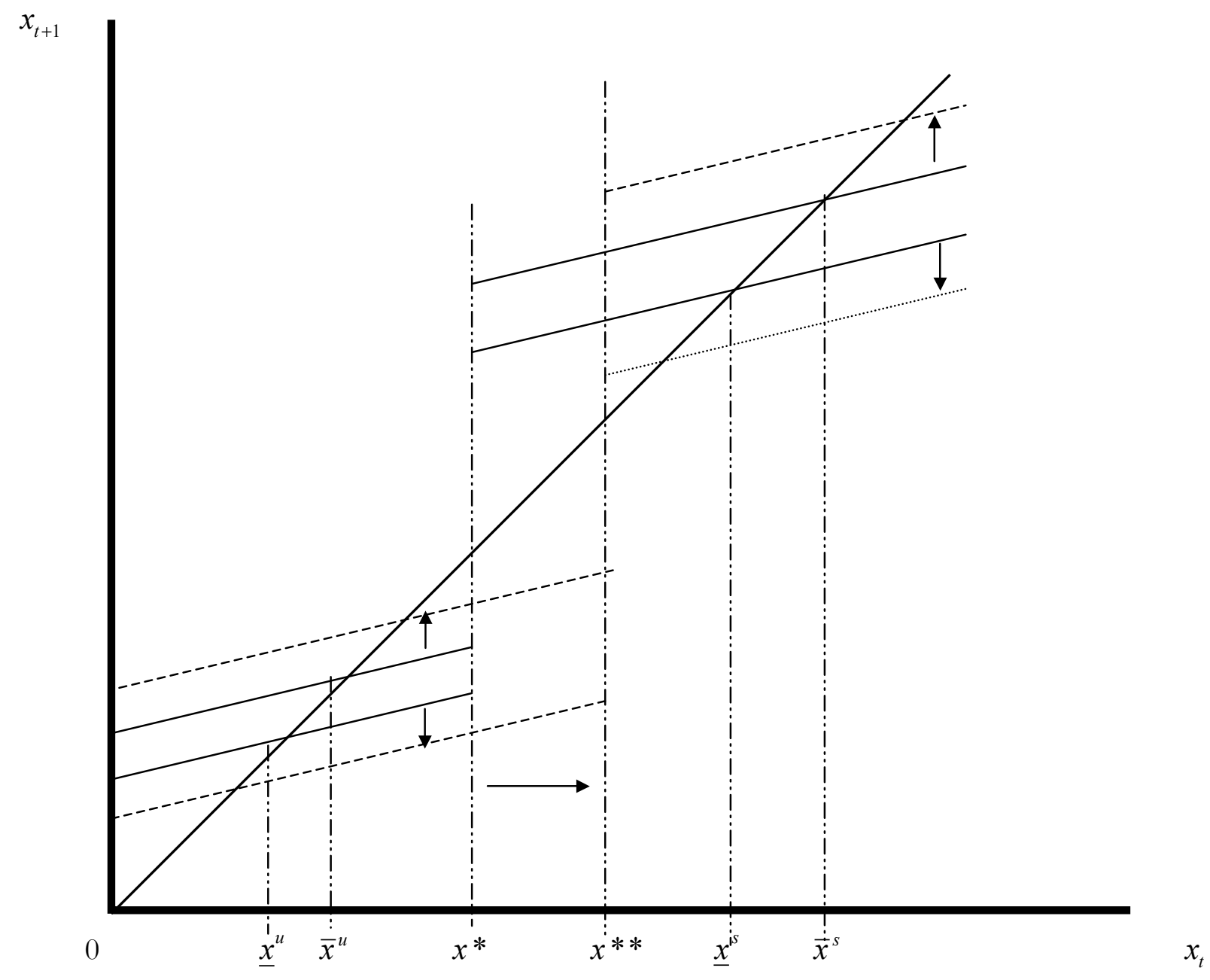

